\title{
Students' Creativity in Virtual vs. Classroom Courses on the Basis of Their Personality Traits: A Prediction Study
}

\author{
Yasamin Abedini \\ University of Isfahan, Iran \\ y.abedini@edu.ui.ac.ir \\ DOI: 10.34190/JEL.18.6.005
}

\begin{abstract}
The present study aims to compare the creativity of students in virtual and classroom courses at University of Isfahan and study its prediction based on the personality traits of these students. The statistical population of the study consisted of all faculty members and students at University of Isfahan in academic year 2017-2018. Among them, 150 subjects were selected using Morgan Table and random sampling method. The data collection was done through Abedi's Creativity Questionnaire (1993) and Costa and McCrae Personality Questionnaire (1992). Data were analyzed by T-test for independent groups, Pearson correlation coefficient and multiple regression analysis. Results show that there is a significant difference in creativity scores of students attending virtual courses and those attending classroom courses, as well as between female and male students. However, the relationship between personality traits and creativity was significantly stronger among classroom students than the virtual students, and these traits were better predictors of creativity in classroom students than in virtual students. Based on findings, it can be concluded that more usage of the information and communication technologies such as internet, wireless networks, cell phone, etc. (ICTs) by virtual students not only increases their creativity, but also, as an important environmental and intrapersonal factor, affects the relationship between personality traits and creativity among these students and weakens it. This finding shows the great role of acquisitive-digital factors in students' creativity.
\end{abstract}

Keyword: creativity, personality traits, students, virtual courses, gender differences

\section{Introduction}

Creativity or creative thinking is among the most important cognitive skills that practitioners in the field of education around the world are interested in examining its nature and its cultivation. The importance of creativity can be emphasized at individual, social, economic, environmental, and educational levels. From the viewpoint of education, the importance of creativity lies in its power to find solutions and solve problems that are in line with life and the changing world. In this regard, Ocon (2006, quoted by Best et al.,2007) believes that innovation and creativity are the only way to survive in a world subject to rapid change, where its security is subject to ever-increasing dangers.

Many years ago, it was thought that creativity was a separate ability specially gifted people, who were able to utilizes this skill and be distinguished in different fields. Lately, psychologists (Craft, 2011, quoted by Nikolopoulou, 2018) argue that creativity is not a special skill or ability of a few individuals, but rather is the result of specific education and learning. Creativity can be regarding as not only a quality finds in exceptional individuals but also as an essential life skill through which people can develop their potential to use their imagination, to express themselves, and to make original and valued choices in their lives. There are many definitions for creativity and innovation that can be examined from different cognitive, behavioral, and cognitive-social perspectives. A first attempt to define the concept was made by Guilford (1986). He believed that creativity covers the most typical capabilities of creative individuals that determine the probability for a person to express a creative behavior, which manifests itself via invention, synthesis, and planning. This behavior seems to be linked with certain personality characteristics, which have speculated whether and how this behavior will be expressed. Getzels and Jackson (1962, quoted by Gunwanan et al., 2018) define creativity as the combination of those elements which are considered original and different. Recently, Santrock (2004) defines creativity as the ability to think about things in new and unusual ways and to reach unique solutions for problems. Some psychologists (torrance,1979, quoted by Pavon and Pavon, 2017) distinguished the qualitative elements of creativity as the flexibility of thinking, the originality of ideas, the ability to think differently, and the ability to solve problems. Torrance test of creativity consists of four subscales: fluidness, expansion, innovation, and flexibility, and now it is one of the most valid tools for measuring creativity.

Regardless of the many varied definitions and perspectives on the nature and dimensions of creativity, one of the key questions in the area of creativity is related to the factors influencing creativity and its development. Hence, over the last few decades, specialists in the fields of education, psychology, and in particular educational 
psychology have been interested in looking at the personality traits of the people who are creative, and they have witnessed a new wave of research in this field (Stein, 1974; Torrance, 1998; Batteson, Tormy and Ritchi, 2014; Karwowski, et al., 2013; Latifian, 2014; Pasha Sharifi, 2014; Lotfi, 2016).

There is a long history for the research on the personality traits of creative people and it is not a thing of the recent decades. So far as Stein (1974, as cited in Seif, 2017) has studied the conducted research on personality traits of creative people, he has found the following features: high achievement motivation, high curiosity, discipline orientation and order in the works, the power of self-expression and self-sufficiency, unconventional and ambitious personality, perseverance and discipline in the works, independence, intuition, and the power to influence others. However, Travers (1977) has said that these traits, although suggest the creative person has a lovely and interesting personality, these people are not necessarily the loved ones by their colleagues and associates. In fact, the opposite story is correct. Defining the personality traits for creative people and how it affects their creativity, Torrance (1988) also maintained that personality can both make creativity easier and to be a stoppage for it. This theorist believes that features such as readiness to risk, curiosity, independence in thinking, perseverance and consistency, courage, and engagement in affairs are among the easiest ways to creativity, and features such as dominancy, negativity, resistance, fear, faultfinding, critique of others, compromising, surrender to power, and low self-esteem are the obstacles against creativity. In the same vein, Sternberg (2006) is one of the new theorists who in his theory, entitled "Personality Investment Theory", suggests that creativity consists of six distinct but interlinked sources: the mental abilities, knowledge, styles of thinking, motivation, environment, and personality. From his point of view, personality traits such as the tendency to remove obstacles and to embrace risks and challenges, the tendency to tolerate uncertainty and ambiguity and high self-efficacy with creative performance are related. For example, the results of the research by Karwowski et al. (2013) indicated a positive and significant relationship between the three factors of the big five personality factors: extraversion, openness to experience, and conscientiousness with creative self-efficacy and creative personal identity in students. In sum, these theories and researches can be concluded that these researchers and theorists believe that creativity is something internal and innate and emphasize on the role of innate and internal in creativity, so that instead of creative people, they speak about creative characters. However, creativity is not only influenced by internal factors, and the role of external factors in formation and development is very important.

While the research conducted by neurology experts has shown that all babies and children are born with a kind of innate ability (Zaidel and Struzic, 2014), but it has been observed that, parallel to one's growth, some of these children develop their innate creativity and keep it active, and others do not grow their innate talent. Identifying and understanding the underlying cause of this issue is very easy, and it relates to the role of environmental and educational factors that surround these children. Therefore, one can say that the creativity of an adult is the result of the interactions between the internal and external factors of an individual. External factors affecting creativity have a wide range, the most important of which are institutions such as the family, formal and informal education systems, information and communication technologies (ICTs) and mass media, culture, customs, etc. It can be said that among these factors, in the present era, mass media, the existing ICTs and the structure of educational systems of a society are among the most important factors affecting the creativity of individuals. It is because today, each person spends almost half their lifetime in institutions such as schools and universities, but technology has a very strong presence in all aspects of their life. In fact, in today's world, technologies have been integrated with all aspects of human life, and most importantly, their presence become more important every day. So that schools, high schools and universities are no exception to this and have become a hot spot for the presence and growth of technology. In this regard, theorists and researchers in the fields of psychology and educational technology emphasize on the role of the technologies in developing the creativity of students (Kim, et al., 2018; Coursey, et al., 2018). For example, they believe blogging and digital storytelling tools cultivate creative thinking skills in children and adolescents. On the other hand, according to the social dimension of creativity, researchers in this field believe that the virtual world can act as an inspirational source for fostering creative ideas in the field of art, design, architecture, management, etc., and it can facilitate learning, developing knowledge, and getting feedbacks, critiques and criticism from others. It will lead to the formation of learning groups and make it possible to have access to more advanced tools and utilize them (Elmansy, 2019). In fact, membership in various social networks and channels and virtual groups provide individuals with a huge amount of information, stimuli, ideas, methods, approaches, and styles that all facilitate divergent thinking (Mauroner and Breitenborn, 2014; Perry-Smith and Mannucci, 2015; Rizza, 2017 quoted by Kim, et al., 2018; Mayorer, 2016). Researchers in the field of creativity believe that the impact of information and communication technology on creativity can be beneficial, depending on the extent and type of user's use and their personality 
traits (e.g. Kim, et al., 2018; Zhou et al., 2009). In addition, people who possess the motivation and skills to use this technological resources are more creative, competitive, adaptable and employable on the job markets (Pavon and Pavon, 2015) therefore, it can be concluded that research on the relationship between creativity and personality traits with emphasis on the role of ICTs is of particular importance and it has remarkable applications for those who involved in education systems at different level of education. In fact, helping students to think creatively is one of the key goals in higher education. Yet, current criticism on universities around the world suggest that students are not prepared for a world where they are expected to solve messy and unstructured problems that don't have easy answers.

Given the fact that we are currently witnessing the emergence and growth of faculties and virtual and e-learning courses in most universities, both domestic and foreign universities and schools, and as annually, a large number of students are trained through such university courses and are graduated, such students have more technological knowledge in comparison with those who attend classroom courses, and this technological knowledge is an important factor in innovation and creativity (Esjholm, 2019). Also, due to the nature of such colleges and courses, the rate of usage, communication and interaction of virtual course students with ICTs (including the Internet and virtual social networks) is more than students of classroom courses, in the present research, therefore, it is assumed that the degree of creativity of students in virtual courses is more than classroom students. The important point to note here is that the characteristics of the formal-public education system in Iran are such that it not only does not encourage creativity but also suppresses it. due to the large volume of textbooks, the lack of time and a large number of students in the classrooms, teachers only focus on textbooks, and don't consider other books and supplementary activities. They often use lectures method to teach students and do not have access to new educational technologies. Group discussion and question-answers methods are rarely used in the classrooms. The evaluation methods used by the teachers are such that they only measures students' rote memory in classroom assessments conducted by teachers, students' analytical, critical, and creative skills are not emphasized and if a student has a new and creative, but strange idea, it will not be encouraged by teacher and even ridiculed by classmates. Of course, the story does not end here, and all of these problems intensify during high school period. Because, in addition to the cases mentioned above, on the one hand, universities' entrance exams(tests) are only focused on memorizing textbooks content and parents, on the other hand, forced their children to spend all their time on memorizing the textbooks content so that they can enter the university. In this way, the students' creativity body becomes half-dead. This vicious cycle is repeated when these students enter universities and attend to university classes. This is where the half-dead body of students' creativity dies. Now let's see what happens to the creativity of virtual university students. Can e-learning and virtual courses revitalize the half-dead bodies of these students' creativity? In fact, the main question is whether virtual learning can moderate the relationship between personality and creativity in these students as an external moderator variable? And how? Hence the other goal of the present study is to investigate the relationship between students' personality traits and their creativity. Therefore, it is assumed that the relationship between personality traits and creativity in virtual students is weaker than students in classroom courses. In other words, the higher level of creativity in virtual students can be attributed to external factors, such as the higher use of ICTs and better and more diverse quality of virtual education in their universities rather than to their personality and internal factors such as their personality traits.

On the other hand, the results of research on the existence of gender differences in creativity are very heterogeneous, in a way that some of these studies do not show any significant difference in the level of creativity of girls and boys (for example, Chan, 2005; Donell, 2005; He and Wong, 2011). Others have reported girls' scores in creativity tests above boys (for example, Misra, 2003, McCrae et al., 2003; quoted by Baer and Kaufman, 2008), and some others found boys' scores in some of the sub-scales of creativity tests higher than the girls, and in some of them, they are lower than girls (e.g. Fichnova, 2002; Kaufman, under press). In this vein, another objective of this study is to compare the creativity in male and female students.

\section{Methodology}

Considering the fact that the present study aims to determine the relationship between personality traits and creativity in students, its research design is non-experimental and descriptive-correlational. The statistical population is all students of the classroom and virtual courses at University of Isfahan, Iran, in the academic year 2017-2018. Using the Morgan table and random sampling, 150 of these students were selected as sample groups, of which 75 were in the classroom courses and 75 of them were in virtual classes. From the total, 150 graduate students were selected as sample groups, 77 were female and 73 were male students. Due to the fact 
that students of virtual courses at the University of Isfahan can only study in one of the fields of business management, information sciences, women studies, English language studies, law, and Persian language and literature, hence the classroom students were matched with them and selected from the same fields.

\section{Research instruments}

The tools used in this study include Abedi's Creativity Test and NEO Personality Inventory Test.

1. Abedi Creativity Test. This test was made by Abedi (1993) based on the theory of Torrance creativity and consists of 60 three-choice questions. Choice 1 is scored 1 and the creativity marker is low, the second option is scored 2, indicating moderate creativity, and the third option is scored 3, indicating high creativity. The test has four subscales: fluidness, expansion, innovation, and flexibility. The total score of the subject is obtained from his scores in these four subscales. The overall range of scores in this test is between 60 and 180. Abedi (1993) calculated the validity of the four subscales of this test through the test-retest method and the coefficients of $0.85,0.84,0.82$, and 0.80 for its four subscales. Also, the internal consistency of this test was calculated by Azmandi, Villa and Abedi (1996, quoted by Rahnama and Abdolmaleki, 2009) by calculating the Cronbach alpha coefficient and its value for the four subscales of this test, the value of which is equal to $0.75,0.66,0.61$, and 0.61 , respectively.

2. NEO Personality Inventory Test (NEO-FFI-R). This test was prepared by Costa and McCrae (1992) and was standardized in Iran by Anbari (2003) in the form of a thesis for Master of Science in Psychology for studying the pre-university students. There are 60 items (questions), all scoring on a five-point Likert scale (strongly agree=5 and strongly disagree=1). The test has five sub-scales that measure five personality traits such as neuroticism, extraversion, conscientiousness, agreeableness, and openness to experience. Anbari (2003) reported the overall reliability of this test by calculating the Cronbach's alpha coefficient as 0.93 and the coefficients of the five factor's reliability are $0.75,0.82,0.89,0.84$, and 0.82 , respectively. This researcher verified the construct validity of the test using an exploratory factor analysis method, so that the five factors were able to explain $72 \%$ of the total variance of the test.

It should be noted that classroom students' questionnaires were distributed in the classrooms and with the prior permission of the deputy of the faculty and the faculty members, and these questionnaires were completed by these students, and the questionnaires related to the students of virtual courses were distributed among them online, along with an accurate and complete instruction, wherein the purpose of investigation and the confidentiality of information, and the manner in which questionnaires were completed and sent were explained. Data analysis was conducted using Pearson correlation coefficient, multiple regression analysis and independent t-test.

\section{Research findings}

In this section, first descriptive statistics and then research findings are presented.

Table 1: Mean, standard deviation, and minimum and maximum student ages

\begin{tabular}{|l|l|l|l|l|l|}
\hline Age & Number & Mean & SD & Minimum & Maximum \\
\hline Virtual & & 29.98 & 3.56 & 25 & 37 \\
students & 75 & 27.24 & 3.01 & 24 & 31 \\
$\begin{array}{l}\text { Classroom } \\
\text { students }\end{array}$ & 75 & & & & \\
\hline
\end{tabular}

As shown in Table 1, the age mean for the virtual students is almost 2 years higher than the classroom students.

Table 2: Mean, Standard Deviation, Minimum and Maximum Student Score in Creativity Test

\begin{tabular}{|l|l|l|l|l|l|}
\hline Creativity & Quantity & Mean & SD & Minimum & Maximum \\
\hline Virtual & & & & & \\
$\begin{array}{l}\text { Students } \\
\text { Classroom } \\
\text { students }\end{array}$ & 75 & 99.59 & 13.43 & 90 & 145 \\
\hline
\end{tabular}

As you can see, the mean score of creativity in virtual students, about 19 points is higher than the average score of creativity in classroom students. 
Table 3: Mean, standard deviation, minimum and maximum scores related to the NEO-FFI-R in classroom students

\begin{tabular}{|l|l|l|l|l|}
\hline Personality Traits & Mean & SD & Minimum & Maximum \\
\hline neuroticism & 20.05 & 6.86 & 5 & 42 \\
\hline Extraversion & 28.86 & 6.32 & 15 & 44 \\
\hline Openness to experience & 27.45 & 4.78 & 17 & 39 \\
\hline Agreeableness & 31.90 & 5 & 17 & 43 \\
\hline Conscientiousness & 32.01 & 6.80 & 18 & 48 \\
\hline
\end{tabular}

As shown in Table 3, the average score of students in personality traits in neuroticism is 20.05in extraversion is 28.86, in Openness to experience is 27.45in Agreeableness is 31.90 and in conscientiousness is 32.01 .

Table 4: Mean, standard deviation, minimum and maximum scores related to the NEO-FFI-R in virtual students

\begin{tabular}{|l|l|l|l|l|}
\hline Personality Traits & Mean & SD & Minimum & Maximum \\
\hline neuroticism & 20.09 & 7.48 & 6 & 46 \\
\hline Extraversion & 20.54 & 3.45 & 11 & 34 \\
\hline Openness to experience & 30.23 & 6.88 & 20 & 50 \\
\hline Agreeableness & 29.02 & 4.49 & 16 & 41 \\
\hline Conscientiousness & 34.99 & 5.78 & 17 & 46 \\
\hline
\end{tabular}

As shown in Table 4, the mean score of virtual students in personality trait in neuroticism is 20.09, in extraversion is 20.54 , in openness to experience is 30.23 , in agreeableness, 29.02 , and in conscientiousness is 34.39 . Comparison of the results of Table 3 and Table 4 shows that the mean scores for extraversion, agreeableness, are respectively about 8 and 3 scores higher than virtual students, while the mean scores of virtual students in openness to personality traits, experience and conscientiousness are about 3 scores higher than classroom students. In other words, classroom students are more introvert and more consistent than virtual students, while virtual students are more conscient and open to experience than classroom students.

Since one of the objectives of the present study is to compare the creativity of students in virtual and classroom courses, to test this goal, the T test for independent samples was used, the results of which are shown in Table 6. It is necessary to explain that in order to examine the presumption of the normal distribution of the sample, the Kolmogorov-Smirnov test was used, the results of which are given in Table 5.

Table 5: Skewness, kurtosis and normality of the distribution of research variables

\begin{tabular}{|l|l|l|l|l|l|l|}
\hline Groups & Skewness & $\begin{array}{l}\text { standard error } \\
\text { of Skewness }\end{array}$ & kurtosis & $\begin{array}{l}\text { standard error } \\
\text { of kurtosis }\end{array}$ & KS & P \\
\hline Creativity & 0.207 & 0.221 & -0.071 & 0.438 & 0.537 & 0.936 \\
\hline neuroticism & 0.125 & 0.221 & 0.215 & 0.438 & 0.701 & 0.710 \\
\hline Extraversion & 0.005 & 0.221 & -0.610 & 0.438 & 0.773 & 0.588 \\
\hline Openness to experience & 0.174 & 0.221 & -0.267 & 0.438 & 0.683 & 0.739 \\
\hline Agreeableness & -0.300 & 0.221 & 0.165 & 0.438 & 1 & 0.270 \\
\hline Conscientiousness & -0.187 & 0.221 & -0.339 & 0.438 & 0.778 & 0.580 \\
\hline
\end{tabular}

The findings of Table 5 indicate the meeting of the necessary assumptions for conducting relevant statistical analyses. So that the distribution of data in all variables is normal and the data in terms of skewness and kurtosis is in good condition.

Table 6: Independent T-test results to compare the difference between the virtual and classroom students' scores in the creativity test

\begin{tabular}{|lccccc|}
\hline Creativity & Quantity & Mean & SD & T & P \\
\hline Classroom & 75 & 80.88 & 11.15 & 3.008 & 0.001 \\
\hline Virtual & 75 & 99.59 & 13.43 & & \\
\hline
\end{tabular}

As can be seen, there is a significant difference between the level of creativity of virtual students and the classroom students $(P \leq 0.001)$ and virtual students' score of creativity is higher than that of the classroom 
students. In the following, the results of multiple regression analysis are presented to predict students' creativity based on their personality traits.

It is necessary to explain that in order to examine the presumption of the normal distribution of the sample, the Kolmogorov-Smirnov test was used, the results of which previously reported in the table 5.al so, The DurbinWatson test was used to illustrate the independence of the regression model's residuals(errors). the results of the test showed a lack of autocorrelation between model's errors (because of, the obtained value for DurbinWatson statistics was 1.713 , and it is between 1.5 to 2.5 , it is an acceptable value).

Table 7: Pearson correlation coefficients between creativity and NEO-FFI-R in classroom students

\begin{tabular}{lllll}
\hline Criterion variable & Prediction variable & $\mathrm{R}$ & $\mathrm{N}$ & Significance Level \\
\hline & Neuroticism & 0.07 & 75 & 0.445 \\
\hline Extraversion & $0.29^{*}$ & 75 & 0.021 \\
\hline Openness to Experience & $0.21^{*}$ & 75 & 0.001 \\
\hline Agreeableness & $0.24^{*}$ & 75 & 0.001 \\
\hline Conscientiousness & 0.17 & 75 & 0.061 \\
\hline
\end{tabular}

Based on the findings of Table 7, the relationship between the three personality traits of Extraversion, Openness to experience, and Agreeableness with creativity is positive and significant in classroom students. This means that with increasing scores of extraversions, openness to experience and agreeableness, creativity scores also increase in these students.

Table 8: Pearson correlation coefficients between creativity and NEO-FFI-R in virtual students

\begin{tabular}{llccc}
\hline Criterion variable & Prediction variable & $\mathrm{R}$ & $\mathrm{N}$ & Significance Level \\
\hline & Neuroticism & -0.09 & 75 & 0.489 \\
\hline & Extraversion & 0.18 & 75 & 0.069 \\
\hline Openness to Experience & 0.19 & 75 & 0.051 \\
\hline & Agreeableness & 0.16 & 75 & 0.074 \\
\hline & Conscientiousness & 0.17 & 75 & 0.061 \\
\hline
\end{tabular}

Based on the findings of Table 8, although the relation between the four personality traits of extraversion, openness to experience, agreeableness, and conscientiousness with creativity is relatively good in virtual students (the range of these correlations varies from 0.16 to 0.19 ), but none of these relationships is significant. Multiple regression analysis was used to more accurately determine these relationships, as well as to determine the share of each of the predictor variables (personality traits) in explaining the criterion variable (creativity), in the students of classroom and virtual courses, that are reported in the following tables.

Table 9: Multiple correlation coefficient (regression coefficient) to predict creativity in students of classroom courses

\begin{tabular}{|lcccc|}
\hline & $\mathbf{R}$ & $\mathbf{R}^{\mathbf{2}}$ & Adjusted $\mathbf{R}^{\mathbf{2}}$ & Standard error of the mean \\
\hline Model & 0.385 & 0.148 & 0.111 & 15.59 \\
\hline
\end{tabular}

The results of Table 9 show that the reported values for $R, R^{2}$, and adjusted $R^{2}$ are at the acceptable level and indicate the fit of the regression model. Also, considering the significance of $F$ in analysis of variance of personality scores and creativity $(P<.01$ and $F=3.96)$, the effect of predictive variable on the criterion variable can be statistically accepted. Since the value of the regression coefficient is significant, the standardized and non-standardized regression coefficients table can be used to determine the significance of the predictor variable in determining the criterion variable. 
Table 10: Standardized and non-standardized regression coefficients

\begin{tabular}{|c|c|c|c|c|c|}
\hline \multicolumn{3}{|c|}{ Non-Standardized coefficient } & \multicolumn{3}{|c|}{ Standardized coefficient } \\
\hline Variables & stan & ard deviation & Beta & $\mathrm{T}$ & Significance Level \\
\hline (constant) & 107.917 & 17.896 & - & 6.142 & 0.000 \\
\hline Neuroticism & 0.029 & 0.249 & 0.019 & 0.106 & 0.949 \\
\hline Extraversion & 0.722 & 0.292 & 0.276 & 2.473 & 0.015 \\
\hline Openness & 0.897 & 0.397 & 0.328 & 3.454 & 0.021 \\
\hline Agreeableness & 0.738 & 0.361 & 0.223 & 2.046 & 0.043 \\
\hline Conscientiousne & ss 0.032 & 0.274 & 0.013 & 0.117 & 0.907 \\
\hline
\end{tabular}

With regard to the significant levels reported in Table 10, three dimensions of the five dimensions of personality can predict the level of creativity in the classroom students. Regarding the reported values for beta coefficients, the change in the size of a standard deviation in the personality traits of extraversion, openness to experience, and agreeableness, respectively, resulted in, $0.276,0.328$, and 0.223 of the standard deviation of the change in creativity of these students. According to the above table, the regression equation is as follows.

$(0.738 \times$ agreeableness $)+(0.897 \times$ openness to experience $)+(0.722 \times$ extraversion $)+107.917=$ Creativity of classroom students

In the above equation, the number 107.917 is constant and the regression coefficient for extraversion is 0.722 , for openness to experience is 0.897 and for agreeableness, it is 0.738 .

It should be noted that multiple regression analysis was used to predict the creativity of virtual students. The following table gives the results.

Table 11: Multiple correlation coefficient (regression coefficient) for the prediction of creativity in virtual students

\begin{tabular}{|llccc|}
\hline & $\mathbf{R}$ & $\mathbf{R}^{\mathbf{2}}$ & Adjusted $\mathbf{R}^{\mathbf{2}}$ & Standard error of the mean \\
\hline Model & 0.342 & 0.117 & 0.102 & 14.99 \\
\hline
\end{tabular}

The reported values for $R, R^{2}$, and adjusted $R^{2}$, in Table 11 are at an acceptable level and indicate the fit of the regression model. Also, with regard to the significance of $\mathrm{F}$ in variance analysis test of personality and creativity scores, the effect of predictive variable on the criterion variable can be accepted statistically $(P<0.05, F=3.13)$.

Table 12: Standardized and non-standardized regression coefficients

\begin{tabular}{|c|c|c|c|c|c|}
\hline \multicolumn{3}{|c|}{ Non-Standardized coefficient } & \multicolumn{3}{|c|}{ Standardized coefficient } \\
\hline Variables & B $\quad s$ & standard deviation & Beta & $\mathrm{T}$ & Significance Level \\
\hline (Constant) & 103.256 & $6 \quad 16.820-$ & - & 5.103 & 0.000 \\
\hline Neuroticism & 0.027 & 0.265 & 0.002 & 0.012 & 0.179 \\
\hline Extraversion & 0.123 & 0.292 & 0.076 & 0.473 & 0.129 \\
\hline Openness & 0.072 & 0.310 & 0.001 & 0.022 & 0.144 \\
\hline Agreeableness & 0.039 & 0.261 & 0.223 & 0.046 & 0.806 \\
\hline Conscientiousn & 0.687 & 0.274 & 0.213 & 2.236 & 0.037 \\
\hline
\end{tabular}

With regard to the significant levels reported in Table 12, conscientiousness is only among the five dimensions of personality able to predict the level of creativity in virtual students. Regarding the reported values for beta coefficients, a change in the magnitude of a standard deviation in conscientiousness personality leads to a change in the standard deviation of students' creativity by 0.213 . According to the above table, the regression equation is as follows. 
$($ Conscientiousness $\times 0.687)+103.256=$ Virtual Students' Creativity

In the above equation, the number 103.256 is the constant in the regression and the regression coefficient for conscientiousness is 0.687 .

In order to examine the difference between creativity of female and male students, the independent t-test was used.it should be mentioned that the assumptions of independency and homogeneity of the variances were checked in groups. Levine's test was used to check the homogeneity of the variances. The results of the test showed the homogeneity of the variances ( $F=0.317, P \leq$. 0.598).

Table 13: The results of independent t-test for examining the difference between general creativity and quadruple subscales of creativity in male and female students

\begin{tabular}{lcccccc}
\hline Creativity & Group & Quantity & Mean & Standard Deviation & T & Significance Level \\
\hline Innovation & Girls & 77 & 20.96 & 3.78 & $4.05^{*}$ & 0.003 \\
& Boys & 73 & 25.89 & 4.95 & & \\
\hline Fluidness & Girls & 77 & 28.51 & 4.42 & $8.52^{*}$ & 0.001 \\
Fluidness & Boys & 73 & 22.42 & 3.20 & & \\
\hline Flexibility & Girls & 77 & 26.54 & 5.77 & $4.96^{*}$ & 0.011 \\
Flexibility & Boys & 73 & 21.22 & 3.51 & & \\
\hline Expansion & Girls & 77 & 23.28 & 4.66 & $9.11^{*}$ & 0.001 \\
Expansion & Boys & 73 & 29.34 & 5.56 & & \\
\hline Total Score & Girls & 77 & 99.29 & 4.66 & 1.12 & 0.234 \\
Total Score & Boys & 73 & 98.87 & 4.31 & & \\
\hline
\end{tabular}

Findings of Table 13 show that although the total score of girls and boys in the creativity test is not significantly different, female students have significantly higher scores in fluidness subscales $(P \leq 0.01)$ and Flexibility $(P \leq 0.05)$, while male students received significantly higher scores in innovation subscales $(P \leq 0.05)$ and expansion $(P \leq 0.01)$ in comparison with female students.

\section{Discussion and Conclusion}

The purpose of this study was to compare the creativity of virtual and classroom students at the University of Isfahan and study its prediction based on the students' personality traits. The findings of the research showed that students of virtual courses have significantly higher creativity than classroom students. These findings are in line with the findings of Nachmias and Shany (2002). By studying 110 students from the eighth and ninth grades who enrolled and participated in an online classroom, they found that among these students, there is a positive and significant relationship between the Liberal Learning Style (from the six learning styles that Sternberg suggests in his theory of Mental Self Government) and creativity. It should be noted that people with a tendency to a liberal learning style have elements of inner motivation. The researchers conclude that the conceptual technological knowledge is small and it constrains the students' abilities in innovation, geniality, and creativity, and vice versa. Therefore, it can be concluded that the virtual students in this study were equipped with more technological knowledge and this has made them more creative. The other possible reason for the greater creativity of the virtual students is related to the better quality of virtual courses. Because the professor of the virtual universities compare to their counterparts in face-to-face universities does not have any limitations in terms of time and space, so, they provide the students with a variety of educational contents in terms of content and format. For example, e-books, articles, educational videos, slides, pictures etc. The students also have no time and space limitations. they can deal with these contents according to their personal learning styles. They can access these contents quickly and whenever they want. Virtual university professors also use a variety of methods to evaluate their students. Their evaluations are usually done with the aim of assessing the high level of the Bloom's cognitive goals such as analytical, critical and creative skills, and all of these increase the creative potential of the students. The findings of the European commission's survey (2014-2015) supports these points, so that $80 \%$ of teachers and students considered as important the ICT tools: computers, educational software, videos, online collaborative learning tools, virtual learning environments, interactive whiteboards, online free material, and online courses. In this regard, Loveless (2007) investigated the characteristics of the digital technologies that allow learners to be creative: interactivity, multiple types/forms of information, range, speed, and automatic functions, characteristics that allows users to do things that could not be done as effectively, or at all, by using other tools. For example, ICT tools enables users to make changes, to try out alternatives, and to keep the traces of the development of their ideas. Interactivity engages the learners-users at different levels, from playing games (which provide feedback to users' decisions) to monitoring-recording the results of an experiment (which again provide immediate and dynamic feedback). Additionally, the speed and automatic 
functions allows the ICT operations of storage, transformation, and display of information, so that students can engages in higher cognitive levels (e.g., interpretation, analysis, and synthesis of information). The recognition of the specific characteristics of the digital technologies (ICT tools) allows learners and teachers to decide when and how to use them. One of the key affordances of the digital technologies is that content or knowledge can be created, shared, and discovered much more quickly and easily (Henriksen, Mishra and Fisser, 2016, quoted by Nikolopoulou, 2018). The new technologies have much to offer to the world of creative sharing: for example, new applications for content development/creation, sharing videos/ audio/images across global contexts, and websites that allows the diverse creators to share content (such as YouTube).

The findings showed that the classroom students are more extrovert and have more agreeability than the virtual students, while the virtual students are more open to experience and have more Conscientiousness than the classroom students. These findings are consistent with Cohen and Baruth's research findings (2017), Denphaisarry (2014, quoted by Kim, et al., 2018), Ramirez-Corea, et al. (2016) and Kim, et al. (2018). By studying virtual students, the researchers found that the three personality traits of openness to experience, conscientiousness and agreeableness were the best predictors for making these students satisfied with the virtual courses. The results of the Denphaisarry's research suggests a strong, meaningful and positive relationship between the conscientiousness personality trait and attitudes toward technologies, and a strong, meaningful negative relationship between the extraversion personality trait and attitudes toward technologies in students. Ramirez-Corea, et al. (2019) also, indicate that the personality type plays an essential role as a moderator of the technology acceptance at work. Kim, et al. (2018) in their article entitled 'Social Networks and Individual Creativity: The Role of Individual Differences' have pointed out that the extent to which individuals take advantage of their social ties may vary depending on individual characteristics, based on the componential model and the investment theory of the creativity. Building on an interactional approach, they explored the role of individual differences in the relationship between social networks and individual creativity and have proposed that weak ties enhances the creativity when information recipients are highly open to experience, have more domain knowledge, have an innovative style, and are intrinsically motivated.

Probably, one of the reasons for turning these students into virtual universities is their being introvert, which makes them more interested in communicating with the cold world than connecting with the warm and human world and attending classrooms. It can also be said that virtual students are likely to have more self-regulatory and self-controlling skills; therefore, they are more responsible (Conscientiousness) and task-oriented than the classroom students and have more time management skills. Thus, without direct supervision and control of the professors and other monitoring systems are able to carry out their study assignments and tasks.

The Findings also showed that the relationship between personality traits and creativity was stronger among classroom students than virtual students, so that the three personality traits of extraversion, openness to experience and agreeableness were able to significantly predict creativity in these students. While the only significant predictor of the creativity in the virtual students was the conscientiousness personality trait. These findings suggest that, in today's digital age, learners' cognitive abilities and creativity are more influenced by the factors that are in the outside world than they are influenced by their personal and internal factors, such as the educational systems and the cultural tools that these systems possess. These tools include digital technologies such as the internet, social networks, virtual worlds, etc., which not only enhance the technological knowledge of the learners, but also facilitates their creativity and innovation with their capacities (Esjholm, 2019). These findings are in line with the research results and theories of the educational technology field, including Mauroner and Breitenborn, 2014; Perry-Smith and Mannucci, 2015; Rizza, 2017, quoted by Kim, et al., 2018; Mauroner, 2016. According to the present study findings, it is suggested that the professors of the face-to-face universities also, use blended /combined learning methods. The methods such as synchronous and asynchronous e-learning. In synchronous learning, the learners and the teachers are online and interact at the same time from different locations. They deliver and receive the learning resources via mobile, video conference, internet or chat. In this type of learning the participants can share their ideas during the session and interact with each other and they get detailed queries and solutions. In asynchronous e-learning, the learner and the teacher cannot be online at the same time. Asynchronous e-learning may use the technologies such as email, blogs, discussion forums, eBook's CD, DVD, etc. Learners may learn at any time, download documents, and chat with teachers and also with co-learners.

Findings of the present study showed that male and female students have a significant difference in terms of the dimensions of creativity. Girls have lower scores in innovation and expansion, and boys have lower scores in flexibility and fluidity. However, the difference of their overall score in creativity is not significant. These findings 
are consistent with the findings of Fichnova, 2002, Abraham,2015; Matud, Rodriguez, and Grande, 2007; He and Wong, 2011; and Kufman (under publication). Such differences can be attributed to the role of internal or genetic factors, especially to the different brain functions and structures of girls and boys, as well as to the socialization and acquired cultural-social factors.

Regarding gender differences in the brain functions or structures, it can be said that some studies have taken gender differences in to account as a covariate or interactional factor in interpreting the relation between creativity and brain structure and function (e.g., Takeuchi, et al., 2015). To date, only two EEG studies (Fink and Neubauer, 2006; Razumnikova,2004), one structural neuroimaging study (Ryman et.al.,2014), and one functional neuroimaging study (Abraham, 2014) have been published which specifically addressed the question of the gender-based brain-related differences in creativity (Abraham, 2015). Fink and Neubauer (2006) found that although no behavioral differences emerged between the sexes on a measure of originality, males and females of different verbal ability significantly differed with respect to task-related synchronization of EEG alpha activity in their anterior region of the cortex. Females in the high ability group demonstrated stronger synchronization with originality than those of average verbal intelligence, whereas the opposite pattern was seen among males. Razumnikova (2004), in contrast suggested that gender differences are instantiated in terms of the hemispheric organization of the brain activity during creative thinking. Ryman's et al. (2014) findings also shows gender differences in the pattern of the white matter connectivity between brain regions, particularly within the default mode and cognitive control networks, as a function of creative ability.

Abraham (2015) believes that sociocultural explanations have been more widely discussed in the context of accounting for gender differences in behavioral performance, particularly in the context of creativity. Societal, cultural and socialization factors have been put forward to explain why men and women demonstrates different levels of creative achievements. Societal constraints include different standards of success for men and women, women not being allowed to participate to the same degree as men in different spheres of life, and active discrimination which negatively impacts access to the resources that are essential for achievement in the certain fields (Simonton, 1992, quoted by Pagnani, 2011).

Cultural factors also have an enormous impact on creativity as cultures differ considerably with regard to genderbased rules, roles and assumptions. Not only are cross-culture differences reflected in the pattern of the genderrelated creative achievement, but even transformations within a culture also accompany changes in genderrelated differences in creative achievement (Simonton, 1992, quoted by Pagnani, 2011).

Socialization differences have also been put forward to explain gender differences in creativity (Piirto, 1991, quoted by Matud, Rodriguez and Grande, 2007). These include gender labeling, different perceptions and expectations for daughters compared to sons, variation in schooling and other important resources.

One of the research constraints is the selection of a sample group from among the undergraduate students of the University of Isfahan, which makes it impossible to extend the results to other students and other universities and institutes of higher education. Due to the fact that researches have shown that there is significant relationship between education level, field of study and students' creativity (e.g., Matud, Rodriguez and Grande, 2007) therefore, the findings of the present study should be generalized to other students with caution. For example, Matud, Rodriguez and Grande (2007) examine the relevance of sociodemographic factors on gender differences in creative thinking. They assessed their subject's creativity thinking with the figural and verbal Torrance test of creative thinking (TTCT) and found statically significant interaction between gender and educational levels on figural fluency, figural originality, resistance to premature closure, figural creativity index, and verbal TTCT scores of fluency, originality, and average standard scores. The women with a university education level scored higher than those with secondary educational levels on all measures. It is recommended that the next researchers select its sample group from other education levels and other universities. In addition, the majority of the classroom students at the University of Isfahan are natives and come from small towns and villages around the Isfahan. Many of these students have limited access to information and communication technologies (ICTs) and digital devices such as laptops, iPads, smartphones, and high-speed Internet. Therefore, caution should be exercised when generalizing the results of the present study to the students of the universities in the large cities and the capital. Given the impact of technology on the creativity of learners, researchers who are interested in the field of creativity, using experimental designs that are conducted under fully controlled conditions, study the impact of the technologies such as virtual social networks on the learners' creativity. 


\section{References}

Abedi, J.,1993. Creativity and a new way of measuring it. Psychological Research, 1, 1 (2), pp. 21-37.

Abraham, A., 2014.Creative thinking as orchestrated by semantic processing vs. cognitive control brain networks. Frontiers in Human Neuroscience,8, pp.95-100. https://doi.10.3389/fnhum.2014.00095.

Abraham, A., 2015. Gender creativity: An overview of psychological and neuroscientific literature. Brain Imaging and Behavior,4, pp. 1-10. https://doi. 10. 1007/ s 11682-015-9410-8

Anbari, A., 2003. Reliability, validity and standardization of the NEO FFI for pre-university students. Master's Degree in Psychometrics, Islamic Azad University of Roodehen. Faculty of Psychology.

Baer, J. and Kaufman, J.C., 2008. Gender differences in creativity. Creativity Research Journal, 4 2(2), pp.74-105.

Batteson, T.J., Tormey, R. and Ritchie, T.D., 2014. Approaches to learning, metacognition and personality: as exploratory and confirmatory factor analysis. Procedia - Social and Behavioral Sciences, 116, pp. $2561-2567$.

Best, T., Berin, A., Thomas, J., and Will, P., 2007. Creative teaching guide: A tool for creative teaching, training and learning. Translated from English by A. Jamshidian, S. Motamedi, and H. Qasemi. Isfahan: Afsar Publications.

Chan, D.W., 2005. Self- perceived creatively, family hardiness and emotional intelligence of chines gifted student in Hong Kong. Journal of Secondary Gifted Education.16, pp. 47- 56.

Cohen, A. and Baruth, O., 2017. Personality, learning and satisfaction in fully online academic courses. Computers in Human Behavior, 72, pp. 1- 12.

Costa, P. T. and Mccrae, R.R., 1992. Revised Neo personality inventory (NEO - P I - R) and NEO five - factor inventory (NEO - FFI) Professional Manual, Odessa, FL: psychological Assessment Resources.

Coursey, L.E., Williams, B.C., Kenworthy, B.J., Paulus, P. B. and Doboli, S., 2018. Divergent and convergent group creativity in an asynchronous online environment. Journal of Creative Behavior, 57(4), pp.221-242.

Donnell, P. N.,2005. The relationship between middle school gifted students' creativity test scores and self-perceptions regarding friendship, sensibility and divergent thinking variables. Published Ph.D. dissertation, Texas AEM University.

Elmansy, R.,2019. How social media affect creativity. [online] Available at: http:// www.designorate.com [Accessed19August 2019].

Esjeholm, B. T.,2019. The relation between students' creativity and technological knowledge in cross- curricular technology and design projects. Finn mark University College.

European Commission. ,2014-2015. ICT research and innovation for creative industries and cultural heritage. [online]. Available at: http://www.openscience.gr/el/news.[Accessed 10 November 2015].

Fichnova, K.,2002. Creative abilities of preschool-age boy and girls / Tvorive schopnostic chlopcov a direct predskorskeho veko. Psychologia a Patopsychologia Dietata, 37, pp. $306-374$.

Fink, A., and Neubauer, A.C., 2006.EEG alpha oscillations during the performance of verbal creativity task: Differential effects of sex and verbal intelligence. International Journal of Psychophysiology, 62(1),pp. 46- 55. https://doi.10.1016/j.ijpsycho.2006.01.001.

Guilford, J. ,1986. Creative talents: their nature, uses and development. New York: Beardly. Limited.

Gunwanan, A., Hariono, H., Sahidu, F., and Nisrina, B., 2018.Improving students' creativity using cooperative learning with virtual media on static fluidal concept. IOP. Conference. Series: Journal of Physics: Conference Series 1006 (2018) 012016.https:// doi :10.1088/1742-6596/1006/1/012016.

He, W.J., and Wong, W.C., 2011. Gender differences in creative thinking revisited: finding from analysis of variability. Personality and Individual Differences, 5(11), pp. 807- 811. https://doi.org/ 1001.16/j. paid.2011.06.027.

Karwowski, M., Lebuda, I, Wisniewska, E. and Gralewski, J. ,2013. Big five personality traits as the predictors of creative self-efficacy and creative personal identity: does gender matter? Journal of Creative Behavior, 3(47), pp. $215-232$.

Kaufman, J. C., (in press) Self- reported differences in creativity by gender and ethnicity. Journal of Applied Cognitive Psychology.

Kim, S.K., Shin, S. J., Shin. J. and Miller, D.,2018. Social networks and individual creativity: the role of individual differences. Journal of Creative Behavior, [e-journal]_53(4), pp.125-143. https://doi.org/10.1002/jocb.153

Latifian, M., Afrouz, GH., and Shahsavarani, A.M.2016. The relationship between the characteristics of mothers with the creativity of the girls. Quarterly Journal of Applied Psychological Research, 5(2), pp. 29-46.

Lotfi, R.,2016. Investigating the relationship between personality traits and creativity in primary and secondary school principals in Zarin Shahr area. Master's Degree in Educational Management, University of Isfahan, Faculty of Educational Sciences and Psychology.

Loveless, A. ,2007. Creativity, technology and learning - A review of recent literature. update. [pdf] . Available at:

http://archive.futurelab.org.uk/resources/documents/lit_reviews/Creativity_Review_update.pdf. [Accessed 10 November2015],

Matud, M., Rodriguez, C., and Grande, J., 2007. Gender differences in creative thinking. Personality and Individual Differences, 43, pp.1137-1147. https://doi.10.1016/ j. paid.2007.03.006.

Mauroner, O. and Brietenborn, H., 2014. The impact of social media on divergent thinking and creativity: A study of knowledge worker in Germany. Paper presented in Institute of knowledge asset management- IKAM-: IFKAD 2014, 9 international Forum on knowledge asset dynamics. Knowledge and management models for sustainable growth. Matera, Italy, 11- 13 June (9) 2014. pp.1346-1365.

Mauroner, O., 2016. Social media for the purpose of knowledge creation and creativity management: A study knowledge worker in Germany. International Journal of Learning and Intellectual Capital, 2 and 3(13), pp. 167- 183. 
Misra, A.,2003. Openness to experiences: gender differences and its correlates. Journal of Personality and Clinical Studies, 19, pp.41- 51.

Nachmias, R. and Shany, N.,2002. Learning in virtual courses and its relationship to thinking styles. Journal of Educational Computing Research, 27(3), pp. 315- 329.

Nikolopoulou, K.,2018. Creativity and ICT: theoretical approaches and perspectives in school. In: T.A. Mikropoulos, ed.2019. Research on e-learning and ICT in education. New York: Springer.ch.5.

Pagnani, A.R.,2011. Gender differences. In: M.A. Runco and S.R. Prizker, eds., Encyclopedia of Creativity. pp. 55- 557. San Diego: Academic. [online]Available at: http:// www.Science direct.com/Science/ article/Pii/B9780123750389001060.

Pasha Sharifi, H., 2014. The relationship between creativity and personality traits of high school students in Tehran. Quarterly Journal of Educational Innovation, 7, pp. 31 - 11.

Pavon, M., and Pavon, F.,2015. Physical education and ICTs as tools to improve communication in Education. Hachetetepe,11, pp. 63-79.

Pavon, M., and Pavon, F., 2017.The use of ICTs and the 4P's of creativity and innovation in education. In: handbook of the management of creativity and innovation.pp.99-115. [online]Available at: https://www.researchgate.net/publication/317064027. [Accessed 5 May 2020].

Perry-Smith, J.E., and Mannucci, P. V.,2015. Creativity, social networks and entrepreneurship. In: C.E. Shalley Y M.A. Hitt. and J.Zhu ,eds.,2018. The Oxford Handbook of Creativity, Innovation and Entrepreneurship. New York: Oxford University Press.

Rahnama, A., and Abdolmaleki, J. 2009. The study of the relationship between emotional intelligence and creativity with academic achievement in Shahed University Students. New Educational Thoughts, 5 (2), pp. 55-78.

Ramirez-Correa, P., Grandon, E., Ealfaro-Perez, J., and Painen-Aravena, G., 2019.Personality types as moderators of the acceptance information technologies in organizations: a multi group analysis in PLS- SEM. Sustainability,11, pp.39-87. [online]Available at: http://www.mdpi.com/journal/sustainability.[Accessed 5 May 2020]. doi:10.3390/su11143987.

Razumnikova, O.M.,2004. Gender differences in hemispheric organization during divergent thinking: An EEG investigation in human subjects. Neuroscience Letters, 362(3), pp. 192- 195.https://doi.10.1016/i.neulet.2004.02.066.

Ryman, S. G.,Van den Huvel, M. P., Yeo, R.A., Caprihan, A., Carrasco, J., Vakhtin, A. A. and Jung,R.E.,2014. Sex differences in the relationship between white matter connectivity and creativity. Neuroimage, 101, pp.380- 389. https://doi.10. 1016/j.neuroimage.2014.07.027.

Santrock, J. W., 2004. Educational psychology .2 $2^{\text {nd }} \& 3^{\text {rd }}$ ed. New York: McGraw-Hill.

Seif, A.A., 2017. New training psychology: psychology of learning and education. $7^{\text {th }}$ ed rev. Tehran: Doran Publishing.

Stein, M.I.,1974. Stimulating creativity. New York: Academic Press.

Sternberg, R.J., 2006. The nature of creativity. Creativity Research Journal, 18(1), pp. 87-89.

Takeuchi, H., Taki, Y., Hashizume, H., Sassa, Y., Nagase,T., Nouchi, R and Kawashima, R., 2012.The association between resting functional connectivity and creativity. Cerebral Cortex ,22 (12), pp.2921-2929.https://doi.10. 1093/ cercor/bhr371.

Torrance, E.P.,1998. An interview with E. Paul Torrance: about creativity. Journal of Educational Psychology Review, 1, pp. $441-452$.

Travers, R.M.W. ,1977. Essentials of learning .4 $4^{\text {th }}$ ed rev. New York: Mc Millan.

Zaidel, D.W.and Struzik, Z.R.,2014. Creativity, brain and art: biological and neurological considerations., Frontiers in Human Neuroscience 8, pp.1- 9.

Zhou, J., Shin, ShJ., Brass, D.J., Choi, J. and Zhang, Zh. S.,2009. Social networks, personal values and creativity: Evidence for curvilinear and interaction effects. Journal of Applied Psychology, 94(6), pp. 1544- 1552. 